\title{
SERUM GONADOTROPINS SECRETION IS NOT REDUCED WITH ADVANCING AGE IN HIV-INFECTED FEMALES: RESULTS OF A CASE-CONTROL STUDY IN MENOPAUSAL WOMEN
}

\author{
Diazzi $C^{1,2}$, Brigante $\mathrm{G}^{1,2}$, Guaraldi $\mathrm{G}^{3}$, Simoni $\mathrm{M}^{1,2}$, Rochira $\mathrm{V}^{1,2}$ \\ ${ }^{1}$ Unit of Endocrinology, Department of Biomedical, Metabolic and Neural Sciences, University of Modena and Reggio Emilia, Italy \\ ${ }^{2}$ Azienda USL of Modena, Italy
}

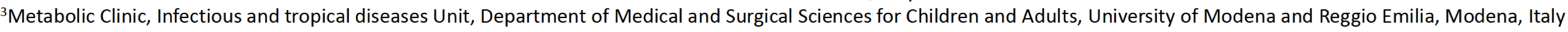

\section{INTRODUCTION}

HIV infection treated with highly active antiretroviral therapy (HAART) seems to be associated with hypogonadism in men. Less is known in HIV-infected women gonadal status. The aim of this study is to investigate gonadal function, in menopausal HIV-infected women compared to sex and age-matched Healthy Subjects (HS)

\section{METHODS}

We retrospectively compared 188 HIV-infected women with 192 healthy women selected reviewing record charts and laboratory database, respectively. We considered only women older than 50 years and we grouped them according to their age $(50-54 ; 55-59 ; \geq 60$ years). Basal serum LH, FSH, Estradiol; and testosterone were measured. The FSH cut-off of $40 \mathrm{mlU} / \mathrm{mL}$ for establishing menopausal status.

\section{RESULTS}

The percentage of subjects with FSH levels $>40 \mathrm{mIU} / \mathrm{mL}$ was higher in HIV-infected women (67.5\%) than in healthy controls (59.4\%) (Figure 1a). This difference was found also in the younger subgroup ( $59.5 \%$ vs $49.5 \%$ ) (Figure 1b). FSH serum levels in HIV-infected women $(54,08 \pm 31.47 \mathrm{mUl} / \mathrm{mL})$ did not differ $(p=0.27)$ from healthy subjects $(50,87 \pm 31 \mathrm{mUl} / \mathrm{mL})$. Accordingly, no significant differences were found in $\mathrm{LH}$, estradiol and testosterone levels (Table 1, Table 2).

\begin{tabular}{|l|c|c|} 
& HIV & HS \\
& $\mathrm{n=188}$ & $\mathrm{n}=192$ \\
\hline Age (years) & Mean \pm SD (min-max) & Mean \pm SD (min-max) \\
\hline LH $(\mathrm{mlU} / \mathrm{mL})$ & $54.63 \pm 4.99(50-71)$ & $56,09 \pm 6,20(50-77)$ \\
\hline FSH $(\mathrm{mlU} / \mathrm{mL})$ & $30.10 \pm 18.62(0.1-90.1)$ & $30,01 \pm 17,86(0-88,06)$ \\
\hline Estradiol $(\mathrm{pg} / \mathrm{mL})$ & $54,08 \pm 31.47(0.3-147.8)$ & $50,87 \pm 31(0-134,71)$ \\
\hline Testosterone $(\mathrm{ng} / \mathrm{mL})$ & $36,55 \pm 60.39(10-397)$ & $40,95 \pm 62,53(0-356,49)$ \\
\hline
\end{tabular}

Table 1: Gonadal status in HIV infected women compared to Healthy subjects (HS). Data are shown as mean $\pm \mathrm{SD}$ and minimum and maximum.

\begin{tabular}{|c|c|c|c|c|}
\hline & \multicolumn{2}{|c|}{ HIV $(n=188)$} & \multicolumn{2}{|c|}{ HS (n= 192) } \\
\hline & $\begin{array}{c}\mathrm{FSH}<40 \\
\mathrm{n}=61(32,5 \%)\end{array}$ & $\begin{array}{c}\mathrm{FSH} \geq 40 \\
\mathrm{n}=127(67,5 \%)\end{array}$ & $\begin{array}{c}\mathrm{FSH}<40 \\
\mathrm{n}=78(40,6 \%)\end{array}$ & $\begin{array}{c}\mathrm{FSH} \geq 40 \\
\mathrm{n}=114(59,4 \%)\end{array}$ \\
\hline & $M e a n \pm S D(\min -\max )$ & $M e a n \pm S D(\min -\max )$ & $M e a n \pm S D(\min -\max )$ & Mean \pm SD $(\min -\max )$ \\
\hline Age (years) & $\begin{array}{c}53.19 \pm 5.23 \\
(50-71)\end{array}$ & $\begin{array}{c}55,32 \pm 4,75 \\
(50-70)\end{array}$ & $\begin{array}{c}55,03 \pm 6,09 \\
(50-77)\end{array}$ & $\begin{array}{c}56,82 \pm 6,20 \\
(50-76)\end{array}$ \\
\hline LH (mlU/mL) & $\begin{array}{c}12.49 \pm 8,38 \\
(0.1-39.9)\end{array}$ & $\begin{array}{c}38.56 \pm 15,97 \\
(12,5-90.1)\end{array}$ & $\begin{array}{c}16,77 \pm 12,07 \\
(0-57,44)\end{array}$ & $\begin{array}{c}39,08 \pm 15,36 \\
(11,4-88,06)\end{array}$ \\
\hline $\begin{array}{l}\text { FSH } \\
(\mathrm{mlU} / \mathrm{mL})\end{array}$ & $\begin{array}{c}19.11 \pm 12.23 \\
(0.3-39.1)\end{array}$ & $\begin{array}{c}70.86 \pm 22.85 \\
(40.9-147.8)\end{array}$ & $\begin{array}{c}21,10 \pm 11,81 \\
(0-39,87)\end{array}$ & $\begin{array}{c}71,24 \pm 22,33 \\
(40,82-134,71)\end{array}$ \\
\hline $\begin{array}{l}\text { Estradiol } \\
\text { (pg/mL) }\end{array}$ & $\begin{array}{c}72.17 \pm 86,79 \\
(10-397)\end{array}$ & $\begin{array}{c}20.15 \pm 32.32 \\
(10-324)\end{array}$ & $\begin{array}{c}77,40 \pm 84,17 \\
(0-356,49)\end{array}$ & $\begin{array}{c}16,02 \pm 15,42 \\
(0-78,8)\end{array}$ \\
\hline $\begin{array}{l}\text { Testosterone } \\
(\mathrm{ng} / \mathrm{mL})\end{array}$ & $\begin{array}{c}62.40 \pm 91.86 \\
(10-466.9)\end{array}$ & $\begin{array}{c}32.41 \pm 18.33 \\
(10-128)\end{array}$ & $\begin{array}{c}43,36 \pm 21,96 \\
(11-134)\end{array}$ & $\begin{array}{c}44,07 \pm 26,58 \\
(0-240)\end{array}$ \\
\hline
\end{tabular}

Table 2: Gonadal status in HIV infected women compared to Healthy subjects (HS) according to $\mathrm{FSH}$ cut-off of $40 \mathrm{mIU} / \mathrm{mL}$. Data are shown as mean $\pm \mathrm{SD}$ and minimum and maximum.
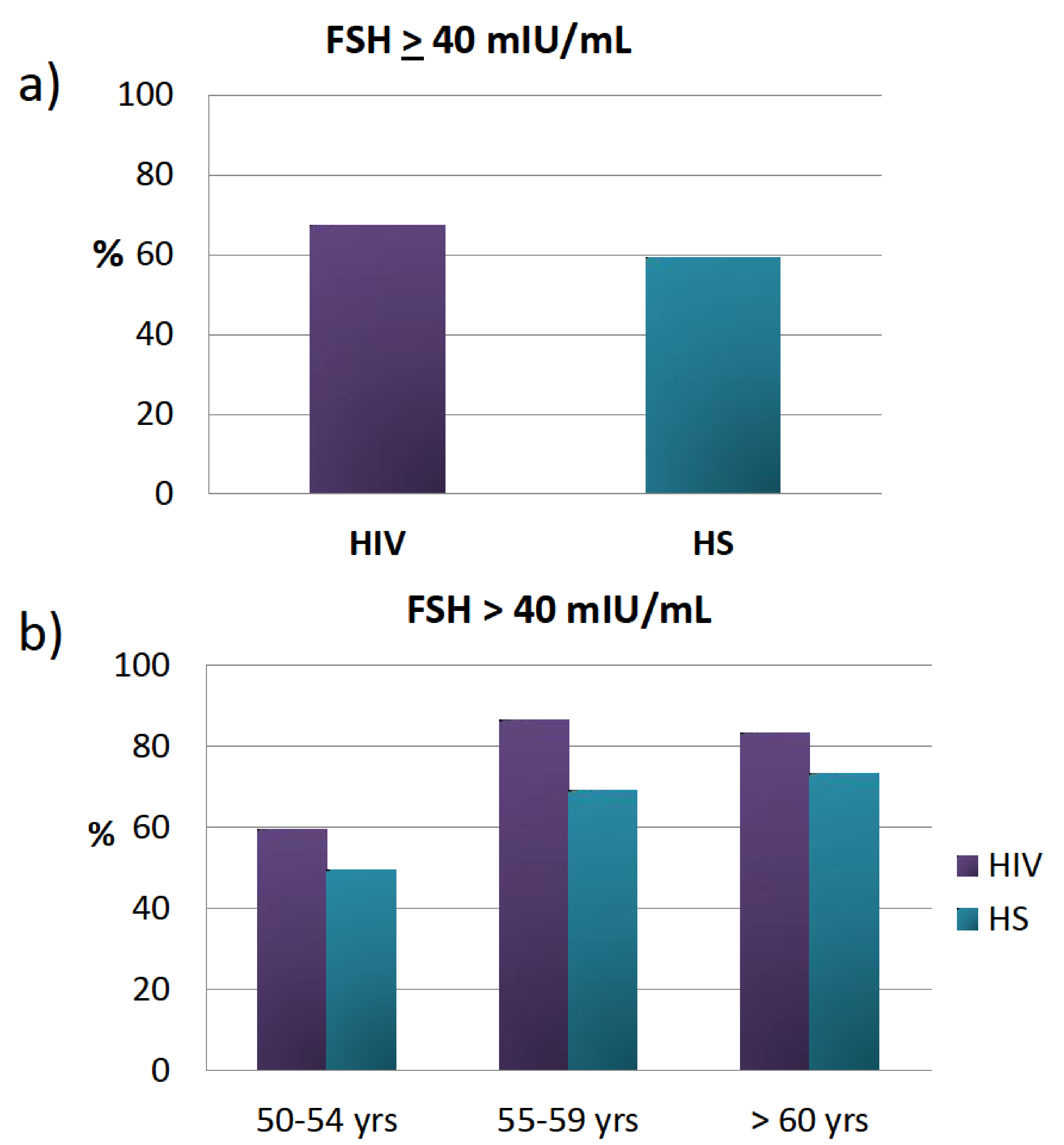

Figure 1: Percentage of HIV infected females compared to healthy controls (HS) with $\mathrm{FSH} \geq 40 \mathrm{IU} / \mathrm{mL}$ (a); Percentage of HIV infected females compared to healthy controls (HS) with $\mathrm{FSH} \geq 40 \mathrm{IU} / \mathrm{mL}$ stratified for age (b)

\section{CONCLUSIONS}

Menopause seems to occur at a younger age than HS in HIV-infected women. Moreover, differently from what was documented in HIV-infected male counterpart, HIVinfected women seem to not develop hypogonadotropic hypogonadism, but have a tendency to higher serum FSH at a younger age (<54yrs) suggesting premature hypergonadotropic hypogonadism. With this in view menopause may be considered an element of the process of premature aging associated with HIV infection and its comorbidities. 